\title{
Non-linear Dependencies in Gold and Stock Prices: A Multivariate Analysis
}

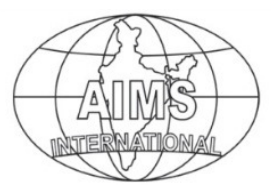

Volume 11, Number 1

January 2017, pp. 21-34

\author{
Afsal E. M \\ Mahatma Gandhi University \\ (afsalemfm@yahoo.co.in) \\ T Mallikarjunappa \\ Mangalore University \\ (tmmallik@yahoo.com)
}

Risk mitigation process is dependent on the predictive capability of models; but no model is perfectly able to capture the price structures. Gold which is one of the hedging tools has attracted less research attention compared to other asset classes. This paper examines the movements of gold price vis-a-vis stock market. A series of univariate and multivariate GARCH models applied discard the dependencies in the two markets. The impulse response validates the results obtained. Hence dynamic relationship among gold and stock market does not exist. However, gold market shows persistence of volatility.

Keywords: Gold Return, Stock Market Return, Multivariate GARCH, Market Spillover, Contagion Effect, Volatility Persistence, Non-linear Dependencies

\section{Introduction}

The relationship of price movements of different classes of investments is of importance for all investors and other stakeholders. In addition, asset price modeling continues to be a most intriguing but reasonably investigated area in financial research. This research is challenging because of two facts; one is lack of consensus about the short and long term behavior of the asset prices in various markets over different time periods. The other is the frequent emergence of powerful econometric tools capable of investigating the market movements. However, unlike pure financial assets such as stocks, bonds or currencies, gold market has received less attention in terms of analyzing the price and return behavior despite standardized international gold market exhibiting data patterns similar to stock or bond markets. The results reported vary from market to market and time to time. For instance, Arouri et al. (2015) in a study of hedging and diversification effectiveness between gold and stocks in China, showed evidence of significant return and volatility cross effects between gold prices and stock prices in China, as well as the superiority of the VARGARCH model over the other multivariate GARCH specifications. Studies of Baur and Lucey (2010) and Chkili, (2016) found that gold is a hedge against stocks on average and a safe haven in extreme stock market conditions. Miyazaki and Hamori (2013) detected bidirectional causality from stock to gold in mean during pre-crisis period but only a unilateral causality in mean and variance for the period of financial turmoil.

Apart from the significance of gold as a secure asset, gold price is used as an economic indicator, especially in predicting inflation (Garner, 1995; Koeing, 1996; Haubrich, 1998; and Sam and $\mathrm{Li}, 2004)$. From empirical perspectives, there are evidences suggesting existence of long memory in gold returns (Booth et al (1982). 
Ball et al. (1982), on the other hand, the presence of short-term memory is also identified. The problem of conditional heteroscedasticity is also displayed in gold data (Akgiray et al., 1991; Frank and Thanasis; 1989). Gold being an asset showing attributes of a commodity and a financial asset requires further analysis in the domains of price volatility, persistence and spillover behaviors. International investors switch to investment in gold whenever there is a sign of long bearish trend in the stock market. Therefore, the gold prices and stock market indices move in opposite direction. However, the relationship between gold prices and stock market indices is not a linear one.

In this paper, we investigate the price movements in the gold market to detect nonlinear dependencies. There are clear evidences that economic system does not need to be linear (Piotr and Witold, 2012). A broad category of methods has been employed to examine the issue of price dependencies of various asset classes. Distributional properties of asset returns largely follow stochastic process and are often different from normality (Yin Wong and Kon, 1993). There are evidences of non-stationarity in the return distributions (for example, So, 1987; Ahn and Reinsel, 1990; Antoniou and Pericli, 2005). Considering the distinctive features of the financial time series such as volatility clustering, leverage effects, persistence and memory levels of volatility, researchers used models of ARCH/GARCH family initiated by Engle (1982) and popularized by Bollerslev (1986) and Taylor (1986). However, empirical results show that simple parameterization of a particular type of GARCH models need not necessarily accomplish the objective of describing asset returns (see for example, Andersen et al., 2006, and Bauwens et al., 2006). Therefore, we apply major classes of GARCH model and examine their predictive abilities. Both univariate and multivariate models of GARCH class are employed in this study. In the beginning, the work uses GARCH $(1,1)$ specification to detect the persistence level of volatility. Proceeding further, a series of models are used to study leverage effect, spillover pattern, risk-premium effects, absolute returns and power transformation factors etc. Finally, Diagonal BEKK specification is used to determine the contagion effect between gold and stock markets.

\section{Methodology}

This empirical work uses a variety of GARCH models, as they are found to be the appropriate models in studying financial asset prices and related issues. We begin with basic GARCH $(p, q)$ specification in order to detect the volatility pattern in the gold market and stock market. The model specification is given as follows.

$$
h t=\alpha 0+\sum_{i=1}^{q} \alpha i \varepsilon_{t-i}^{2}+\sum_{j=1}^{p} \beta j h t-j
$$

Where $\alpha_{0}$ captures the long-run average volatility. The terms $\alpha$ and $\beta$ are the ARCH and GARCH coefficients; $q$ is the order of the moving average ARCH terms and $p$ is the number of the autoregressive GARCH terms.

Notably, Standard GARCH model does not allow us to measure asymmetric behaviour of the volatility parameter. In order to understand, how volatility responds to good and bad news, following Abhyankar (1998), we apply Exponential GARCH 
(EGARCH) specification popularized by Nelson (1991). A general conditional variance framework of EGARCH $(1,1)$ is given below.

$\ln \left(h_{t}\right)=\omega+\theta\left[\frac{\mathcal{E}_{t-1}}{\sqrt{h_{t-1}}}\right]+\gamma\left[\left|\frac{\mathcal{E}_{t-1}}{\sqrt{h_{t-1}}}\right|-E\left(\left|\frac{\mathcal{E}_{t-1}}{\sqrt{h_{t-1}}}\right|\right)\right]+\phi \ln \left(h_{t-1}\right)$

According to the EGARCH representation, the variance is conditional on its own past values as well as on past values of the standardized residuals. The persistence of volatility is measured by $\square$ for gold returns. The conditional variances are finite if $\square<1$. The coefficients $\gamma$ measures the ARCH effects and $\theta$ captures the asymmetric behavior. The coefficients of ARCH term, $\gamma$ determines the spillover behavior of the markets in such a way that a significant negative value indicates that for a given decrease in volatility of one market would bring about a decrease in volatility of the other market. Leverage term is expected to be negative to convey that market reacts more to negative news than to positive (good) news. The lag truncation length ( $\mathrm{p}$ and q) is determined using Likelihood Ratio (LR) tests and we choose EGARCH $(1,1)$ specification.

GARCH in Mean and Power ARCH are also used to study the risk premium effects and impact of absolute returns and power transformation. The model frameworks are provided below for both GARCH M and PARCH specifications respectively in equations (3) and (4).

$$
\begin{gathered}
\sigma_{t}^{2}=\omega+\sum_{j=1}^{q} \beta_{j} \sigma_{t-j}^{2}+\sum_{i=1}^{p} \alpha_{i} \varepsilon_{t-1}^{2}+Z_{t}^{\prime} \Pi \\
\sigma_{t}^{\delta}=\omega+\sum_{j=1}^{q} \beta_{j} \sigma_{t-j}^{\delta}+\sum_{i=1}^{p} \alpha_{i}\left(\left|\varepsilon_{t-i}\right|-y_{i} \varepsilon_{t-i}\right)^{\delta}
\end{gathered}
$$

In the multivariate GARCH class of models, many developments have been reported since the first VEC model of Bollerslev et al. (1988). The VEC representation assumes that conditional variance and covariance are functions of their respective lagged values as well as lagged squared returns and cross-products of returns. The model is given below

$$
\text { vech }\left(H_{t}\right)=C+\sum_{j=1}^{q} A_{J} \text { vech }\left(\varepsilon_{t-j} \varepsilon_{t-j}^{\prime}\right)+\sum_{j=1}^{p} B_{j} \text { vech }\left(H_{t-j}\right)
$$

Where vech (') is an operator that stacks the columns of the lower triangular part of argument matrix, $H_{t}$ is the covariance matrix of the residuals, $C$ is an $N(N+1) / 2 X 1$ vector, $A_{j}$, and $B_{j}$ are $N(N+1) / 2 X N(N+1) / 2 X$ parameter matrices and $\varepsilon$ is an $N X 1$ vector (Bollerslev et al ,1988).

Baba, Engle, Kraft and Kroner (1990) introduced a model called BEKK model that ensures positive definiteness. This model can be considered as a restricted version of the VEC model. In this model, a new form of the conditional variance matrix $H_{t}$ was defined. The BEKK Model is given by equation (6).

$$
H_{t}=C C^{\prime}+\sum_{j=1}^{q} \sum_{k=1}^{K} A^{\prime} K j \varepsilon_{t-j} \varepsilon^{\prime}{ }_{t-j} A_{k j}+\sum_{j=1}^{p} \sum_{k=1}^{K} B^{\prime}{ }_{k j} H_{t-j} B_{k j}
$$


Where $H_{t}$ represents the conditional variance-covariance matrices; $A_{k j}, B_{k j}$ and $C$ are $N X N$ parameter matrices and $C$ ' is a lower triangular matrix.

The first order BEKK model is given by equation (7).

$H_{t}=C C^{\prime}+A^{\prime} \varepsilon_{t-1} \varepsilon^{\prime}{ }_{t-1} A+B^{\prime} H_{t-1} B$

The BEKK model has also its diagonal form by assuming $A_{k j}$, and $B_{k j}$ are diagonal matrices. The BEKK model is not linear in parameters. In this model, the elements of the symmetric matrix $A$ measures the degree of market shocks from stock market to gold market and the elements of the symmetric matrix B indicate the persistence in conditional volatility between the two markets. The model ensures that the conditional variance-covariance matrices $H_{t}$ is positive definite if at least one of $C$ or $B$ is of full rank.

\section{Data Specification}

The study is based on daily observations of gold prices and stock index values. We use Financial Times Stock Exchange 100 index (FTSE-100) and gold prices to study the relationship between the gold and stock price movements. FTSE-100 is taken as a representative stock index in the European region, as this is the stock index of 100 large and active shares listed on the London Stock Exchange (LSE). FTSE 100 daily closing price data is acquired from LSE. The daily gold prices adjusted in Pound are obtained from Bullion Rates. The selection of both price series is from the same market region so as to ensure the logic for comparison. Data synchronization has been made in order to ensure uniformity with respect to time and date for price series of the assets. The number of observations under consideration is 1604 during 2007 to 2014 .

Prices are converted into daily returns for both FTSE 100 and gold prices, calculated as the first difference of the log values of the successive closing prices. Statistical properties of the sample data are given in Table 1 below.

Table 1 Descriptive Statistics

\begin{tabular}{|l|c|c|c|c|c|c|c|c|c|}
\hline & Mean & Median & Maximum & Minimum & $\begin{array}{c}\text { Std. } \\
\text { Dev. }\end{array}$ & $\begin{array}{c}\text { Ske } \\
\text { wness }\end{array}$ & Kurtosis & $\begin{array}{c}\text { Jarque- } \\
\text { Bera }\end{array}$ & Probability \\
\hline $\begin{array}{l}\text { FTSE 100 } \\
\text { Return }\end{array}$ & 0.0028 & 0.0758 & 9.0873 & -10.3285 & 1.4577 & -0.9962 & 14.4807 & 9068.726 & 0.00 \\
\hline $\begin{array}{l}\text { Gold } \\
\text { Return }\end{array}$ & 0.0289 & 0.0424 & 10.68935 & -9.12407 & 1.3580 & -0.3134 & 9.1954 & 2589.958 & 0.00 \\
\hline FTSE 100 & 5557.518 & 5685.801 & 6840.342 & 3512.104 & 695.719 & -0.70163 & 0.0695 & 174.3047 & 0.00 \\
\hline Gold & 4837.071 & 4939.740 & 7131.620 & 2672.260 & 1208.007 & -0.04367 & 1.6273 & 126.3589 & 0.00 \\
\hline
\end{tabular}

Gold returns a better daily return than the stock during the period with a value of 0.0289 as against 0.0028 for the stock index. Standard deviation, a light measure of risk, is less for the gold return compared to stock returns. All the four series show the evidence of skewness and the effect of skewness is negative which describes the departure from the symmetry. The values of kurtosis show more than three in both return series indicating non-normality behavior. In addition, the Jarque-Bera values indicate that we reject the null hypothesis that the price and return series are normally distributed as the associated probability values are all zero. 
In order to check the properties of data, each time series under consideration is subjected to test for stationarity. The Dickey-Fuller test was separately used for price and return series of both stock index and gold prices. Table 2 reports the result of unit root test.

Table 2 Unit Root Test Results

\begin{tabular}{|c|c|c|c|}
\hline & & Test Statistic & p value \\
\hline Gold & $\mathrm{Z}(\mathrm{t})$ & -1.590 & 0.4885 \\
\hline Stock Index & $\mathrm{Z}(\mathrm{t})$ & -1.304 & 0.6272 \\
\hline Gold return & $\mathrm{Z}(\mathrm{t})$ & -39.722 & 0.0000 \\
\hline \begin{tabular}{|l|} 
Stock Index return \\
\end{tabular} & $Z(t)$ & -36.656 & 0.0000 \\
\hline
\end{tabular}

It is evident that stock and gold price series are difference-stationary. The unit root hypothesis (i.e., series is non-stationary) is found true in the closing price series, while the return series are stationary in all the cases. Phillips-Perron test for unit root is carried out on original price series and log return series of both stock index and gold market. The test result is summarized in Table 3. Another test called DF-GLS is also performed as a modified Dickey-Fuller t test for a unit root in which the series has been transformed by a generalized least-squares regression. The maximum lag length is 24 chosen by Schwarz criterion. The result confirms the finding reported earlier at 1 percent, 5 percent and 10 percent intervals. The figures are omitted for brevity. In addition to the tests carried out above, we perform Bartlett's period grambased test for white noise. Bartlett's test is a test of the null hypothesis that the data follow a white-noise process of uncorrelated random variables with a constant mean and a constant variance. The result is presented graphically in Figure 1 for each series under consideration.
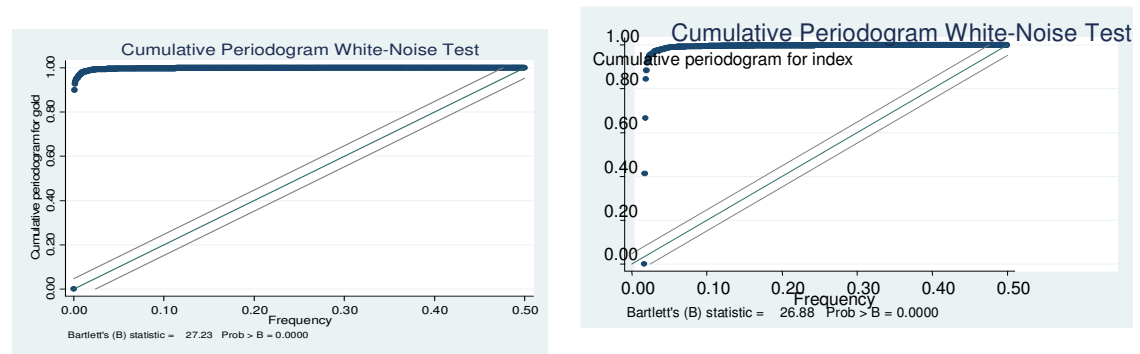

Figure 1 Bartlett's Periodogram

Table 3 Phillips-Perron Test for Unit Root

\begin{tabular}{|cccccc|}
\hline $\begin{array}{c}\text { Gold Test } \\
\text { Statistic }\end{array}$ & $\begin{array}{c}\text { 1\% Critical } \\
\text { Value }\end{array}$ & $\begin{array}{c}\text { 5\% Critical } \\
\text { Value }\end{array}$ & $\begin{array}{c}\text { 10\% Critical } \\
\text { Value }\end{array}$ \\
\hline $\mathrm{Z}(\mathrm{rho})$ & -3.133 & -20.700 & -14.100 & -11.300 \\
$\mathrm{Z}(\mathrm{t})$ & -1.571 & -3.430 & -2.860 & -2.570 \\
- &
\end{tabular}




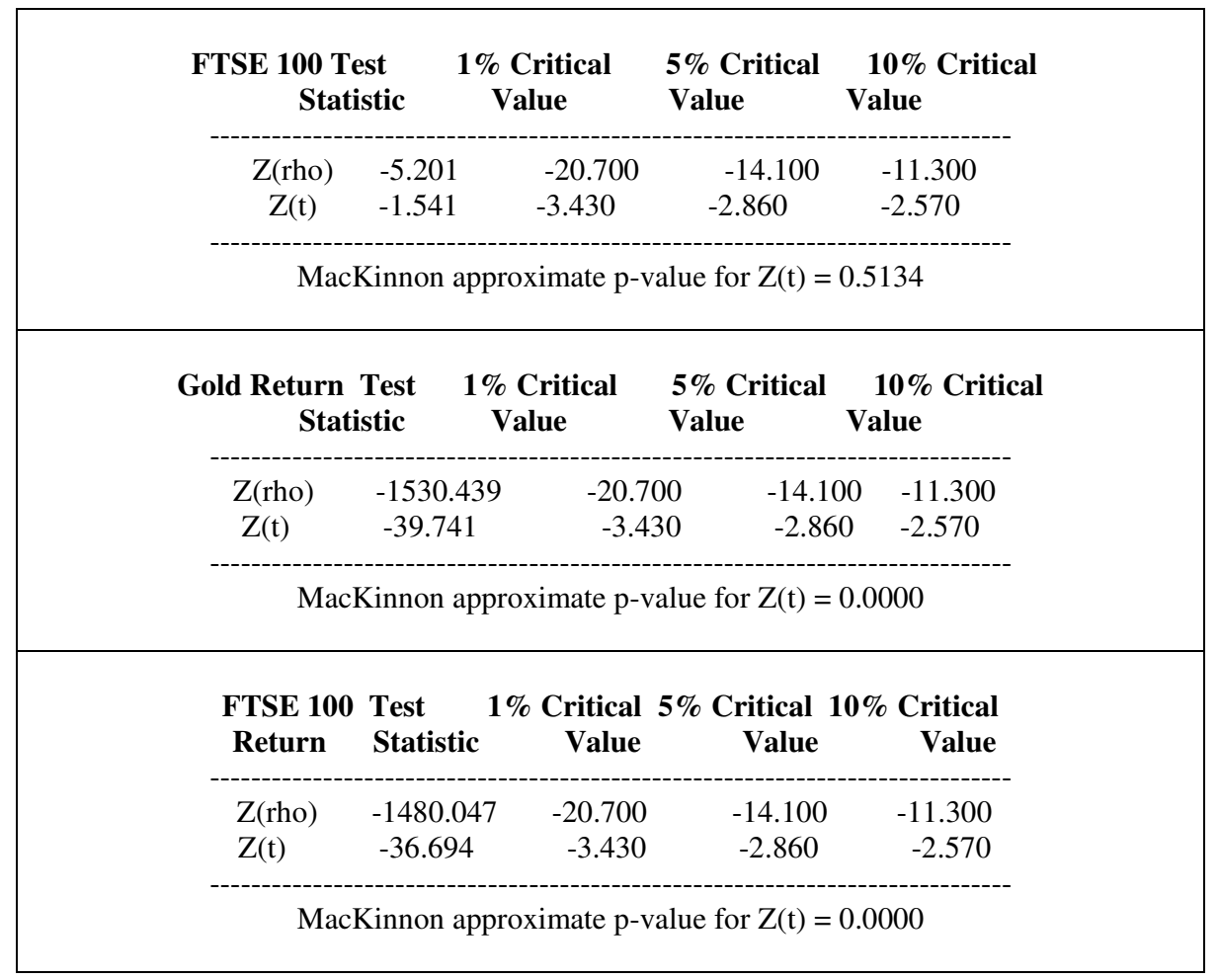

We can observe in the first two graphs for gold and index price series, that the values denoted by dark colored points do appear outside the confidence bands. We also have confirmation from the test statistic, at a p-value of 0.000 , that the process is significantly different from white noise. However, last two graphs for return series for gold and index show that the values fairly appear in the confidence bands. On detecting the non-stationary patterns in the original price series of gold and stock index, different heteroscedastic models from ARCH/GARCH family class are used in this work. Each model checks out the interdependencies between the gold market and stock market during the period.

\section{Results and Discussions}

Various results and findings obtained out of the estimation process are discussed in this part. The results are divided among the areas of volatility clustering, persistence, asymmetric behavior and price interdependence and contagion effects.

\subsection{Volatility Modeling}

On detecting the ARCH effects, we employed a series of models in order to investigate the volatility behavior of the market and also to determine the effectiveness of each model. For the $\operatorname{GARCH}(p, q)$ model, the values of $p$ and $q$ are set one according to the Schwarz Information Criterion (SIC). The results of GARCH $(1,1)$ estimation for index return and gold return are presented in Table 4. 
Table 4 GARCH Estimation Output

\begin{tabular}{|c|c|c|c|c|}
\hline \multicolumn{3}{|c|}{ Dependent Variable: GR (Gold Return) } & \multirow[b]{2}{*}{ z-Statistic } & \multirow[b]{2}{*}{ Prob. } \\
\hline Variable & Coefficient & Std. Error & & \\
\hline $\mathrm{C}$ & 0.088882 & 0.022375 & 3.972417 & 0.0001 \\
\hline \multirow[t]{2}{*}{\begin{tabular}{|l|l} 
TR \\
\end{tabular}} & 0.021905 & 0.017389 & 1.259706 & 0.2078 \\
\hline & \multicolumn{2}{|c|}{ Variance Equation } & & \\
\hline $\mathrm{C}$ & 0.030227 & 0.002675 & 11.30025 & 0.0000 \\
\hline $\operatorname{RESID}(-1)^{2}$ & 0.146044 & 0.013614 & 10.72786 & 0.0000 \\
\hline GARCH(-1) & 0.851042 & 0.010872 & 78.27564 & 0.0000 \\
\hline TR & 0.006277 & 0.009784 & 0.641545 & 0.5212 \\
\hline
\end{tabular}

It is clear that the coefficients of GARCH constant $\left(\alpha_{0}\right)$, ARCH $\left(\alpha_{1}\right)$ and GARCH $\left(\beta_{1}\right)$ are significantly different from zero and are within the parametric restrictions. This implies greater impact of shocks (news) on market returns and presence of volatility clustering. A large shock in a day leads to a large (conditional) variance in the following day, indicating the impact of recent news on price changes. Again, the higher value of GARCH implies long memory of the model to the shocks. More importantly, the gold return is found unaffected by index returns giving a notion that both move independently. The findings also discard the notion of market efficiency because in an efficient market, the gold prices follow stochastic movements leaving no scope for historical analysis to reap any abnormal profit. In an efficient market, asset returns does not exhibit perfect random walk behavior. The results show that many of the chosen factors, including own past information set, explain returns. Figure 2 depicts the volatility patterns of gold market during the sample period. The model does a good job in capturing volatility clustering that has occurred at different intervals as is seen in the plot.
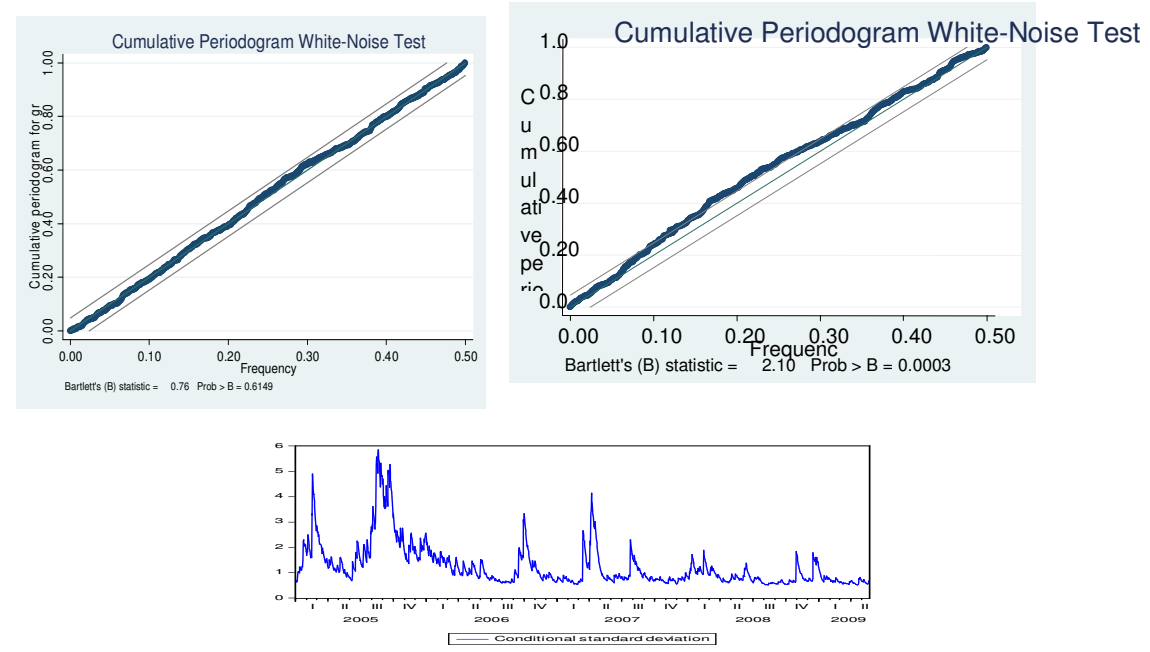

Figure 2 GARCH Volatility Patterns

\subsection{Asymmetric Behavior of Volatility}

EGARCH specification provides a structure of asymmetric nature of market volatility. The appropriate model appears to be EGARCH $(1,1)$ and the estimated 
output is given in the Table 5. In the model specification, all parameters are significant except the index return coefficient. The persistence of volatility is visible and also the asymmetric nature. The gold market volatility is a function of past innovations. A negative value of asymmetric parameter suggests that the market is rather sensitive to bad information than to positive ones. This is a general trend in asset markets.

Table 5 EGARCH Estimation Output

\begin{tabular}{|c|c|c|c|c|}
\hline \multicolumn{3}{|c|}{ Dependent Variable: GR (Gold Return) } & \multirow[b]{2}{*}{ z-Statistic } & \multirow[b]{2}{*}{ Prob. } \\
\hline Variable & Coefficient & Std. Error & & \\
\hline $\mathrm{C}$ & 0.076501 & 0.020665 & 3.701969 & 0.0002 \\
\hline \multirow[t]{2}{*}{ GR } & 0.013101 & 0.014361 & 0.912250 & 0.3616 \\
\hline & \multicolumn{2}{|c|}{ Variance Equation } & & \\
\hline $\mathrm{C}(3)$ & -0.215157 & 0.014745 & -14.59156 & 0.0000 \\
\hline $\mathrm{C}(4)$ & 0.302894 & 0.019546 & 15.49610 & 0.0000 \\
\hline $\mathrm{C}(5)$ & -0.132599 & 0.012312 & -10.76948 & 0.0000 \\
\hline $\mathrm{C}(6)$ & 0.960762 & 0.003359 & 286.0041 & 0.0000 \\
\hline $\mathrm{C}(7)$ & 0.012856 & 0.011854 & 1.084581 & 0.2781 \\
\hline
\end{tabular}

\subsection{Risk Premium Effects}

The return of a security may depend on its volatility (risk). This kind of risk-return relationship is established through GARCH- in- mean (GARCH- M) model which adds a heteroscedasticity term into the mean equation. The mean equation estimation outputs are separately shown for standard deviation and variance in the Table 6 and Table 7. Variance equation parameters are not provided, as the results validate the prior findings and also less relevant in the present context.

Table 6 GARCH $M-S D$

\begin{tabular}{|c|c|c|c|c|}
\hline Variable & Coefficient & Std. Error & z-Statistic & Prob. \\
\hline$(\mathrm{GARCH})^{(1 / 2)}$ & 0.013686 & 0.066381 & 0.206178 & 0.8367 \\
\hline $\mathrm{C}$ & 0.077578 & 0.056387 & 1.375812 & 0.1689 \\
\hline TR & 0.021829 & 0.017395 & 1.254958 & 0.2095 \\
\hline
\end{tabular}

Table 7 GARCH $M$-Variance

\begin{tabular}{|l|c|c|c|c|}
\hline Variable & Coefficient & Std. Error & z-Statistic & Prob. \\
\hline GARCH & 0.004568 & 0.020763 & 0.220028 & 0.8258 \\
\hline C & 0.085235 & 0.026872 & 3.171897 & 0.0015 \\
\hline GR & 0.021885 & 0.017384 & 1.258865 & 0.2081 \\
\hline
\end{tabular}

Symmetric GARCH-in -Mean $(1,1)$ estimates show insignificant but positive riskreturn relationship in the gold market. The volatility coefficient (risk premium) in 
both standard deviation (0.0136) and variance (0.0045) does not reflect a dynamic risk-return pattern. This is against the general notion of a significant risk-return relationship. However, there are evidences for insignificant but positive relationships as reported by Baillie and DeGennarro (1990)

\subsection{Absolute Returns and Power Transformations}

A common finding in much of the empirical finance research is that although asset returns contain certain amount of serial correlation, there exists correlation between absolute returns and their power transformations. Ding et al (1996) investigated the autocorrelation structure of power of the absolute return of daily S\&P 500 and found that absolute return has significant positive autocorrelations for long lags. In order to carry out such an analysis on the gold market, we model the mean equation using an MA (1) process. The test results are provided in Table 8 . We can note that the estimated power GARCH model for the gold return exhibits the high level of persistence (0.842). Therefore, we conclude that the estimated autocorrelations of the power-transformed absolute observations start high, and decrease very slowly.

Table 8 Power ARCH Estimates

\begin{tabular}{|l|c|c|c|c|}
\hline Variable & Coefficient & Std. Error & z-Statistic & Prob. \\
\hline C & 0.078600 & 0.013507 & 5.819394 & 0.0000 \\
\hline GR & 0.004824 & 0.009651 & 0.499813 & 0.6172 \\
\hline \multicolumn{5}{|c|}{ Variance Equation } \\
\hline C(3) & 0.038053 & 0.003737 & 10.18255 & 0.0000 \\
\hline C (4) & 0.175247 & 0.013437 & 13.04240 & 0.0000 \\
\hline C(5) & 0.585338 & 0.042092 & 13.90616 & 0.0000 \\
\hline C (6) & 0.842900 & 0.009847 & 85.60318 & 0.0000 \\
\hline$C(7)$ & 0.007623 & 0.004769 & 1.598236 & 0.1100 \\
\hline$C(8)$ & 0.648987 & 0.079722 & 8.140624 & 0.0000 \\
\hline
\end{tabular}

\subsection{The Contagion Effect between Gold and Stock Markets}

According to Forbes and Rigobon (2002), contagion effect is a significant increase in correlation between markets. Such effects are identified in many empirical researches carried out mainly in the area of stock market and crude oil prices (See Filis, 2010; Mollick and Assefa, 2013 and many others). As mentioned earlier, the gold market received less attention in this regard. The linkage between gold prices and stock market has important implication for investment and hedging. We apply diagonal BEKK- GARCH $(1,1)$ and VECH models to study the volatility spillover between gold market and stock market. Both the models are estimated using maximum likelihood techniques.

Table 9 reports the BEKK- variance-covariance estimated parameters. The conditional variance of the diagonal BEKK-GARCH model includes two variables namely gold return and stock index return. In Table 10, the estimation output of VECH-GARCH specification is presented. 
Table 9 Covariance Specification: Diagonal BEKK

\begin{tabular}{|l|c|c|c|c|}
\hline GARCH = M + A1*RESID(-1)*RESID(-1) $*$ A1 + B1*GARCH(-1)*B1 + E1.*TR \\
\hline & \multicolumn{5}{|c|}{ Transformed Variance Coefficients } \\
\hline & Coefficient & Std. Error & z-Statistic & Prob. \\
\hline $\mathrm{M}(1,1)$ & 0.033954 & 0.002955 & 11.49083 & 0.0000 \\
\hline $\mathrm{A} 1(1,1)$ & 0.379818 & 0.013705 & 1.01400 & 0.0085 \\
\hline $\mathrm{B} 1(1,1)$ & 0.918349 & 0.004714 & 194.8289 & 0.0000 \\
\hline $\mathrm{E} 1(1,1)$ & -0.085160 & 0.003600 & -0.65802 & 0.0056 \\
\hline
\end{tabular}

Coefficient matrix is not Positive Semi Definite.

$\mathrm{M}, \mathrm{A} 1, \mathrm{~B} 1$ and $\mathrm{E} 1$ being indefinite matrix

Table 10 Covariance Specification: Diagonal VECH

\begin{tabular}{|l|c|c|c|c|}
\hline GARCH = M + A1. ${ }^{*}$ RESID(-1)*RESID(-1) & + B1. & $*$ GARCH(-1) + E1.*TR \\
\hline & \multicolumn{5}{|c|}{ Transformed Variance Coefficients } \\
\hline & Coefficient & Std. Error & z-Statistic & Prob. \\
\hline M & 0.231196 & 0.381977 & 0.605261 & 0.5450 \\
\hline A1 $(1,1)$ & 0.759816 & 1.249156 & 0.608263 & 0.5430 \\
\hline B1 $(1,1)$ & 0.843734 & 0.026030 & 32.41422 & 0.0000 \\
\hline E1 $(1,1)$ & $3.14 \mathrm{E}-05$ & 0.138444 & 0.000227 & 0.9998 \\
\hline
\end{tabular}

$\mathrm{M}$ is a scalar and A1, B1 and E1 being rank one matrices. The result shows absence of significant shock transmissions between stock market and gold market. Diagonal BEKK model and VECH model offer similar results that again confirm the findings obtained in the univariate GARCH computations. However, there is evidence of persistence of conditional volatility between the two markets. BEKK standard residuals are plotted in Figure 3.
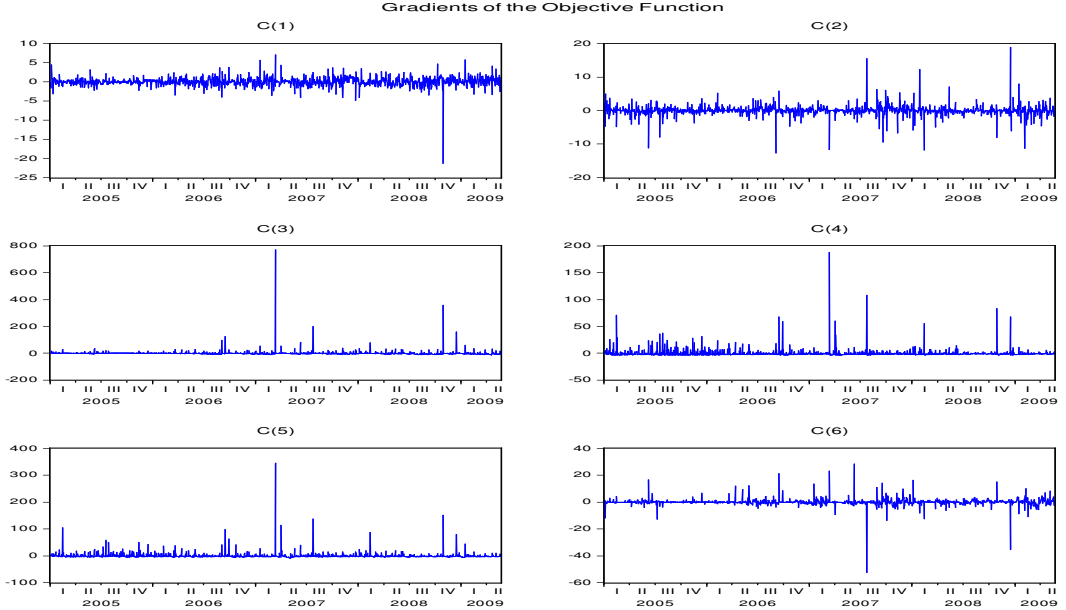

Figure 3 BEKK Standard Residuals

Table 11 shows the test result of GARCH effects on the standardized residuals of the BEKK framework. Based on the results we can conclude that the GARCH effect 
has largely disappeared. From the Ljung-Box statistic based on the auto correlation test, we accept the null hypothesis that it is a random series.

Table 11 Residual Portmanteau Tests for Autocorrelations

\begin{tabular}{|c|c|c|c|}
\hline Lags & Q-Stat & Prob. & df \\
\hline 1 & 0.88162 & 0.0006 & 1 \\
\hline 2 & 0.71680 & 0.0004 & 2 \\
\hline 3 & 0.79141 & 0.0013 & 3 \\
\hline 4 & 0.44785 & 0.0016 & 4 \\
\hline 5 & 0.50997 & 0.0024 & 5 \\
\hline 6 & 0.86376 & 0.0044 & 6 \\
\hline 7 & 0.51723 & 0.0046 & 7 \\
\hline 8 & 0.75244 & 0.0054 & 8 \\
\hline 9 & 0.76894 & 0.0096 & 9 \\
\hline 10 & 0.13589 & 0.0036 & 10 \\
\hline 11 & 0.59078 & 0.0004 & 11 \\
\hline 12 & 0.60517 & 0.0008 & 12 \\
\hline
\end{tabular}

The impulse response graphs plotted in Figure 4 represent how stock index return (TR) responds to shocks of both index equation and gold equation. Similarly, response behavior of gold to shocks of both gold equation and index equation is also depicted in the figure. The line graph in the upper left-hand corner shows that following a shock to the index equation, index twists around for some time, but later the response has effectively dissipated. Gold return (GR) also exhibits similar response to shocks of GR. In contrast, TR and GR are effectively unresponsive to the shocks of each other. This finding reinforces the results obtained in GARCH family estimations. The results of the different models used in this study show that the dynamic and significant relationship among gold price and stock price is absent.
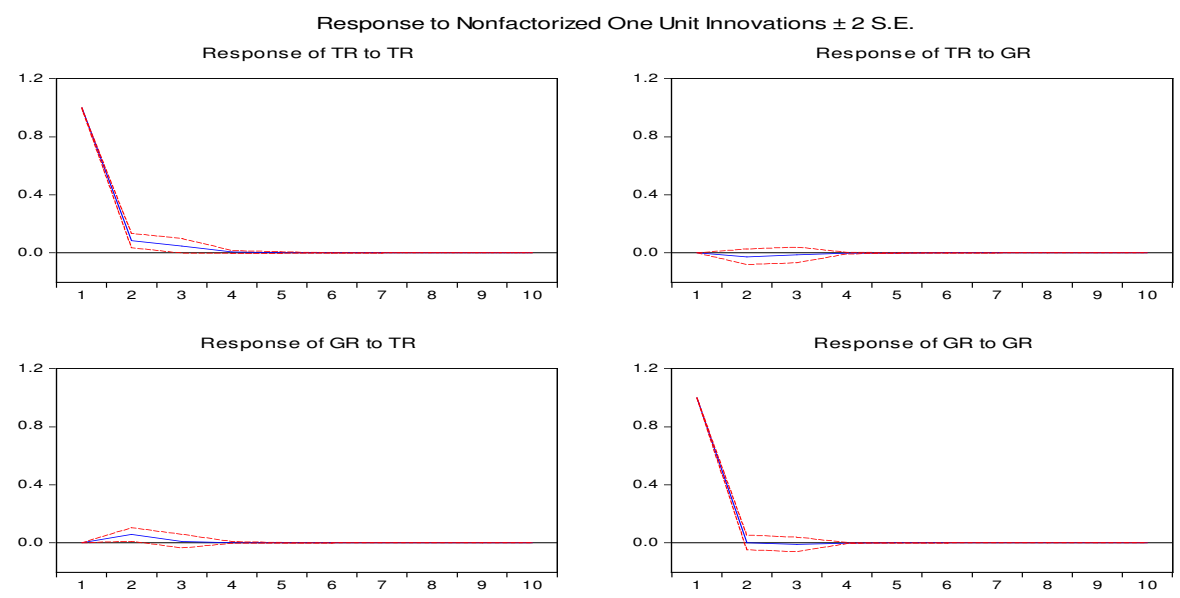

Figure 4 Impulse Response Graphs 


\section{Conclusions}

Investors and portfolio managers are interested to know the relationship between the prices of different assets classes. This relationship helps the portfolio managers to construct and manage efficient portfolios. This paper investigates the relationship between gold and stock market. The results show that there exists no specific interdependence between the stock price and gold price during the investigated period. Lack of spillover may be because of the fact that any innovation originated in one market is offset by other innovation of opposite sign, leading to a weak or zero effect of stock market on gold market as noted by Jorion (1990) for exchange rate volatility. Another possible explanation is that volatility spillovers are neutralized by the effective use of gold for hedging purpose. Also, a minor chance is that different sets of investors operate in two markets with sole focus on either stock or gold investment. A scrutiny of sample of investor profile may also be required to support any argument.

Risk-premium effect is also absent in the case of gold market. However, an insignificant but positive risk-return relationship in the market can't undoubtedly reject the general hypothesis of risk-return togetherness. Persistence of volatility is found in the market in such a way that market is more responsive to negative effects. A common behavior of asset market wherein low returns are followed by lower returns is found in the case of gold market as well.

In brief, neither a bidirectional price spillover nor a volatility transmission occurs between the gold market and stock market during the study period. Portfolio selection is to be more inclusive to gain the potential benefits of hedging in either market.

\section{References}

1. Abhyankar, A., (1998), 'Linear and Nonlinear Granger Causality: Evidence from the UK Stock Index Futures Market', Journal of Futures Markets, Vol.18(5), 519 - 540.

2. Ahn, S. K. and Reinsel, G. C., (1990), 'Estimation for Partially Non-Stationary Multivariate Autoregressive Models', Journal of the American Statistical Association, Vol. 85, -813- 823.

3. Akgiray, Vedat G., Booth, Geoffrey., Hatem, John J. and Chowdhury, Mustafa., (1991), 'Conditional dependence in precious metal prices', The Financial Review, Vol.26 (3), 367-386.

4. Andersen, T., Bollerslev, T., Christoffersen P. and Diebold, F., (2006), 'Volatility and Correlations Forecasting. In: Elliott G, Granger C, Timmermann A (Eds): Handbook of Economic Forecasting. Vol. 1.Elsevier B. V, Amsterdam, North-Holland, 778-878.

5. Antoniou, A., Koutmos, G. and Pericli, A., (2005), 'Index Futures and Positive Feedback Trading: Evidence from Major Stock Exchanges', Journal of Empirical Finance, Vol.12, 219 - 238.

6. Arouri, M. E. H., Lahiani, A., \& Nguyen, D. K. (2015). World gold prices and stock returns in China: insights for hedging and diversification strategies. Economic Modelling, 44, 273-282.

7. Baillie, R. T., DeGennarro, R. P. (1990) "Stock returns and volatility", Journal of Financial and Quantitative Analysis, Vol. 25(5), 203-214. 
8. Ball, C., Torous, W. and Tschogel, A., (1982), 'Gold and the weekend effect', Journal of Futures Markets, Vol.2 (2), 175-182.

9. Bartlett, M. S., (1955), 'An Introduction to Stochastic Processes with Special Reference to Methods and Applications', Cambridge: Cambridge University Press.

10. Baur, D. G., \& Lucey, B. M. (2010). Is gold a hedge or a safe haven? An analysis of stocks, bonds and gold. Financial Review, 45(2), 217-229.

11. Bauwens, L., Laurent, S., Rombouts, J., (2006), 'Multivariate GARCH Models: A Survey', Journal of Applied Econometrics, Vol.21,79-110.

12. Bollerslev T., Engle R.F., Wooldridge J.M., (1988), 'A capital asset pricing model with time varying covariances', Journal of Political Economy, Vol.96, 116-131.

13. Bollerslev,T. (1986),Generalized Autoregressive Conditional Heteroscedasticity, Journal of Econometrics, Vol.31, 307-327.

14. Booth, G., Kaen, F. and Koveos, P., (1982), 'Persistent dependence in gold prices', Journal of Financial Research, Vol. 5 (1), 85-93

15. Chkili, W. (2016). Dynamic correlations and hedging effectiveness between gold and stock markets: Evidence for BRICS countries. Research in International Business and Finance, 38, 22-34.

16. Ding, Z., Granger, C.W.J., Engle, R.F., (1993), 'A long memory property of stock market returns and a new model', Journal of Empirical Finance, Vol.1, 83-106.

17. Engle, R. F., (1982), 'Autoregressive Conditional Heteroskedasticity with Estimates of the Variance of the United Kingdom Inflation', Econometrica, Vol.50, 987-1007

18. Filis, G., (2010), 'Macro economy, stock market and oil prices: do meaningful relationships exist among their cyclical fluctuations?', Energy Economics, Vol. 32(4), 877-886.

19. Forbes, K.J. and Rigobon, R., (2002), 'No contagion, only interdependence: measuring stock and the 2008-2009 financial crisis', Energy Economics, Vol.36, $1-18$.

20. Frank-,_M. and Thanasis, S., (1989), 'Measuring the strangeness of gold and silver rates of return', The Review of Economic Studies, Vol.56 (4), 553-567.

21. Garner, C. A., (1995), 'How useful are leading indicators of inflation?', Economic Review (Federal Reserve Bank of Kansas City), Vol.80 (2), 2-7.

22. Haubrich, J. G., (1998), 'Gold prices', Economic Commentary, Federal Reserve bank of Cleveland, 1-4,

23. Jacky, C. S.,(1987)' 'The Sub-Gaussian Distribution of Currency Futures: Stable Paretian or Nonstationary?', The Review of Economics and Statistics, Vol.69(1), 100-107

24. Jorion, P., (1990), 'The Exchange Rate Exposure of US Multinationals', Journal of Business, Vol.63 (3), 331-45.

25. Koeing, E. F., (1996), 'Should high prices of gold be of concern?', The Southwest Economy, Federal Reserve Bank of Dallas, Vol. 4, 6-9.

26. Miyazaki, T., \& Hamori, S. (2013). Testing for causality between the gold return and stock market performance: evidence for 'gold investment in case of emergency'. Applied financial economics, 23(1), 27-40. 
27. Mollick, A.V. and Assefa, T.A.. (2013), 'US stock returns and oil prices: the tale from daily data market co-movement', Journal of Finance, Vol. 57 (5), 22232261.

28. Nelson, D.B. (1991), 'Conditional Heteroscedasticity in Asset returns: A New Approach', Econometrica, Vol.59(2), 347-370.

29. Piotr Fiszeder and Witold Orzeszko, (2012), 'Nonparametric Verification of GARCH-Class Models for Selected Polish Exchange Rates and Stock Indices', Journal of Economics and Finance, 62( 5), 430-449.

30. Sam, M. and Li, H.C. (2004), 'Gold Price, Neural Networks and Genetic Algorithm', Computational Economics 23(2) 193-200

31. Taylor, S. J. (1986), Modelling Financial Time Series, Wiley, Chi Chester.

32. Yin-Wong Cheung and Kon S. Lai (1993), ' Do Gold Market Returns Have Long Memory?', Financial Review, 28(2), 181-202

\section{About Our Authors}

Afsal E.M. is currently member of faculty of School of Management and Business Studies at Mahatma Gandhi University, Kerala, India. He has got twelve years of experience in industry, academic and research fields in India as well as abroad. Research interest includes derivatives, asset pricing and modeling, economics and strategy. He is the recipient of awards for Best Doctoral Presentation and Best Empirical Paper and published in journals and presented in conferences of national and international stature. He organized various seminars, published books and edited a volume. He is on the editorial board of three major journals. He can be reached at: afsalemfm@yahoo.co.in.

T Mallikarjunappa is a Professor in the Department of Business Administration, Mangalore University, India. He has worked as the Chairman of the Department; Dean of the faculty, Finance Officer, member of the Academic council, Syndicate etc. at Mangalore University. He has 34 years of post-graduate teaching and research experience. He is a Ph.D. from University of Mysore and an Associate Member of the Institute of Cost Accountants of India, Kolkatta. He is on the editorial board of AIMS International Journal of Management and other journals. He is also the reviewer of papers for journals. His papers are published in AIMS International Journal of Management, ICFAI Journal of Applied Finance, Decision, Vikalpa, Asian Academy of Management Journal of Accounting and Finance, etc. His specialization is accounting and finance. He was awarded AIMS International Fellow, by AIMS International, Houston, at 10th AIMS International conference held at IIM, Bangalore. He has other awards like the best teacher in finance, outstanding management teacher and researcher. $\mathrm{He}$ can be reached at: tmmallik@yahoo.com. 